Canadian

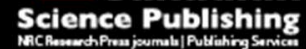

Canadian Journal of Microbiology Revue canadienne de de microbiologie

\title{
Profile of bacteria colonizing the exposed bone of patients with anti-osteoclastic drug-related osteonecrosis of the jaws.
}

\begin{tabular}{|r|l|}
\hline Journal: & Canadian Journal of Microbiology \\
\hline Manuscript ID & cjm-2016-0212.R1 \\
\hline Manuscript Type: & Article \\
\hline Date Submitted by the Author: & 05-May-2016 \\
\hline List of Authors: & $\begin{array}{l}\text { Jabbour, Zaher; McGill University, Faculty of Dentistry; McGill University } \\
\text { Health Center, Research Institute, Bone Engineering Labs } \\
\text { do Nascimento, Cassio; Faculty of Dentistry of Ribeirao Preto, University of } \\
\text { Sao Paulo, Dental Materials and Prostodontics } \\
\text { El-Hakim, Michel; McGill University, Faculty of Dentistry, Division of Oral } \\
\text { and Maxillofacial Surgery } \\
\text { Henderson, Janet E.; McGill University Health Center, Research Institute, } \\
\text { Bone Engineering Labs; McGill University, Faculty of Medicine, Department } \\
\text { of Medicine and Surgery } \\
\text { Albuquerque, Rubens F.; Faculty of Dentistry of Ribeirao Preto, University } \\
\text { of Sao Paulo, Dental Materials and Prostodontics }\end{array}$ \\
\hline Keyword: & $\begin{array}{l}\text { Anti-osteoclastic drug, Jaw osteonecrosis, Bacteria biofilm, DNA } \\
\text { checkerboard, Cancer }\end{array}$ \\
\hline
\end{tabular}


1 Profile of bacteria colonizing the exposed bone of patients with anti-osteoclastic drug-

2 related osteonecrosis of the jaws.

3 Running title: Microbiota of anti-osteoclastic drug osteonecrosis

4 Zaher Jabbour $^{\mathrm{a}, \mathrm{d}}$, Cássio do Nascimento ${ }^{\mathrm{b}}$, Michel El-Hakim ${ }^{\mathrm{c}}$, Janet E Henderson ${ }^{\mathrm{d}, \mathrm{e}}$ and Rubens F.

5 de Albuquerque Junior ${ }^{\mathrm{a}, \mathrm{b}}$.

6 a Division of Restorative Dentistry, Faculty of Dentistry, McGill University, Montreal, QC,

7 Canada.

$8{ }^{b}$ Department of Dental Materials and Prosthodontics, Faculty of Dentistry of Ribeirão Preto,

9 University of Sao Paulo, Brazil.

$10{ }^{\mathrm{c}}$ Division of Oral and Maxillofacial Surgery, Faculty of Dentistry, McGill University, Montreal,

11 QC, Canada.

$12{ }^{\mathrm{d} B o n e}$ Engineering Labs, Research Institute, McGill University Health Center, Montreal, QC,

13 Canada.

$14{ }^{\mathrm{e}}$ Department of Medicine and Surgery, Faculty of Medicine, McGill University, Montreal, QC,

15 Canada.

16 Corresponding author:

17 Dr Rubens Albuquerque

18 Dental Materials and Prostodontics

19 Faculty of Dentistry of Ribeirao Preto

20 University of Sao Paulo

21 Ribeirao Preto, SP, BR

22 rubens.albuquerque@usp.br 


\section{Abstract}

25 Microbial etiology for anti-osteoclastic drug-related osteonecrosis of the jaw (ARONJ) was

26 suggested. This study investigates any link between bacteria colonizing ARONJ sites and other

27 oral cavity sites.

28 Microbiota samples of 10 ARONJ patients were collected from the exposed bone, adjacent teeth,

29 contra-lateral teeth and tongue. DNA checkerboard hybridization was used for microbiota

30 analysis with probes from human genomic DNA of 38 bacterial and 5 candida species guided by

31 Socransky's bacterial complexes. Frequency and mean proportion of each bacterial species were

32 used.

33 E. corrodens, S. constelatus and F. nucleatum were dominant in the ARONJ sites, and detected

34 in most teeth samples. S. aureus was also dominant in ARONJ sites and tongue. Significant

35 correlations were found between mean proportions of bacterial species colonizing adjacent teeth,

36 contra-lateral teeth and tongue $\left(\mathrm{p}<0.001, \mathrm{R}^{2}>0.69\right)$. No significant correlation $(\mathrm{p}>0.05$,

$37 \mathrm{R}^{2}<0.025$ ) was found between bacteria colonizing ARONJ sites and other evaluated sites.

38 Within the study limitations, it was concluded that the primary sources of microorganisms

39 colonizing ARONJ sites could be other sites such as teeth and tongue. The microbial profile of

40 the necrotic bone is predominantly colonized by bacteria from Socransky's green and orange

41 complexes, as well as with species associated with bone infections.

44 Key words: Anti-osteoclastic drug, jaw osteonecrosis, bacteria biofilm, DNA checkerboard, 45 cancer. 


\section{Introduction}

49 Bisphosphonates and receptor activator of nuclear factor kappa-B ligand (RANKL) inhibitors are

50 drugs commonly used to inhibit bone resorption in the management of hematologic cancers like

51 multiple myeloma, metastatic lesion from solid tumors such as breast and prostate, as well as in

52 the treatment of metabolic bone disease like osteoporosis (Bundred 2012; Coleman and

53 McCloskey 2011). Osteonecrosis of the jaw was recognized as a serious complication of anti-

54 osteoclastic and anti-angiogenic drugs (MRONJ) (Ruggiero et al. 2014). Anti-osteoclastic drug-

55 related osteonecrosis of the jaw (ARONJ) was defined as the presence of persistent, exposed,

56 non-healing bone for more than 8 weeks in the maxillofacial region in patients treated with

57 bisphosphonates or RANKL inhibitors but with no history of radiation to the head and neck

58 region (Ruggiero et al. 2014). The etiology of ARONJ remains largely un-defined (Otto et al.

59 2010).

60 In a number of studies, bacterial etiology of ARONJ has been proposed (Hinson et al. 2014;

61 Pushalkar et al. 2014; Sedghizadeh et al. 2012). The human oral cavity represents a reservoir of

62 more than 700 bacterial species that colonize the teeth and mucosal surfaces of the mouth (Aas et

63 al. 2005). Wei et al. used molecular techniques to characterize the microbiota associated with

64 bisphosphonate osteonecrosis and identified Streptococcus, Eubacterium and Pseudoramibacter

65 as the three top genera in these patients compared to Parvimonas, Streptococcus and

66 Fusobacterium in control cancer patients with oral infection but with no history of

67 bisphosphonate exposure (Wei et al. 2012). In another investigation, Ji et al. reported that oral

68 antibiotics had limited effect on the bacterial population colonizing the sites of bone exposure in

69 patients with bisphosphonate osteonecrosis (Ji et al. 2012). Although bacteria seem to play an 
70 important role in the development of ARONJ, the source of bacterial infection is not clear.

71 Therefore, the aim of this study was to determine if the profile of bacterial species colonizing

72 ARONJ sites could be linked to the oral microbiota of other sites of patients with this condition.

\section{Materials and methods}

\section{ARONJ patients}

75 This study was approved by the McGill University Health Center Research Ethics Board.

76 Patients diagnosed and treated for ARONJ at the Oral and Maxillofacial Clinic, Montreal

77 General Hospital, were identified and signed an informed consent to participate in the study. The

78 inclusion criteria were:

79 1- Male and/or female patients aged 18 years and older.

80 2- Patients diagnosed and treated for bone exposure associated with ARONJ stage 1 or 2 81 between April and September 2012.

82 3- Patients receiving oral and/or intravenous bisphosphonates or RANKL inhibitors.

83 Patients with history of radiation to the head and neck area were excluded from the study.

84 Details about patient age, gender, bisphosphonates, co-medications, periodontal health, main 85 complaint and site of bone necrosis were documented.

\section{Microbial sample collection}

87 Microbial samples were collected using a microbrush (Microbrush International, Grafton, WI, 88 USA) by rubbing it till saturation for 30 seconds. The use of microbrush was shown to be a 89 suitable method for microbial biofilm collection (do Nascimento et al. 2009). Given possible 90 inaccuracy in measuring the weight of the samples, we used standard-sized microbrush tips that 
91 are capable to absorb a volume of about $6 \mu \mathrm{L}$. To avoid any contamination, all microbrushes

92 were sterilized and stored in sealed packs before use. At the time of sample collection, the

93 microbrushes were uncovered, and direct collection of sample from the exposed necrotic bone,

94 the supragingival part of the immediately adjacent teeth, the contra-lateral teeth and the dorsal

95 surface of the tongue was obtained. Particular attention was paid to avoid any contact or

96 contamination of the microbrushes with any other sites of the mouth. Immediately after

97 collection, samples were individually disposed into microtubes containing $150 \mu 1$ of TE $(10 \mathrm{Mm}$

98 Tris- $\mathrm{HCl}, 1 \mathrm{Mm}$ EDTA $\mathrm{pH}$ 7.6) and then $150 \mu \mathrm{l}$ of $0.5 \mathrm{M}$ sodium hydroxide to cause cell lysis and

99 expose genetic material, according to protocol proposed by Socransky et al. (1994). Next, the

100 microtubes were transported to the laboratory and stored at $4^{\circ} \mathrm{C}$ till DNA checkerboard

101 hybridization. Sample collection did not cause any pain or discomfort to the patients and was

102 performed without local anaesthesia.

103 DNA checkerboard hybridization

104 Bacterial and fungal DNA hybridization was performed using the checkerboard method as

105 described previously (do Nascimento et al. 2010; Jabbour et al. 2013; Sunde et al. 2000).

106 Hybridization probes were prepared by direct labeling (Amersham Gene Images AlkPhos Direct

107 Labelling and Detection System, GE Healthcare, Buckinghamshire, UK) of genomic DNA from

108 the 38 bacterial and 5 candida species listed in Table 1. Bacterial probe selection was based on

109 relevance of the species to human oral health and guided by bacterial complexes described by

110 Socransky et al. (Socransky et al. 1998). Suitable specificity and sensitivity of these probes were

111 already tested and optimized for the detection of $10^{4}$ cells (Socransky et al. 2004). Bacterial and

112 fungal whole-genomic DNA extracted from biofilm samples from patients were denatured, 
113 precipitated and blotted onto the hybridization membrane (Hybond $\mathrm{N}+$, Amersham Biosciences,

114 Buckinghamshire, UK) using MiniSlot 30 apparatus (Immunetics, MA, USA). As reference

115 samples, defined amounts of genomic DNA corresponding to either $10^{5}$ or $10^{6}$ cells of each

116 analyzed target species were mixed in a single tube, denatured, precipitated and applied on the

117 membranes. Samples were fixed on the hybridization membrane using vacuum and baked for 2

118 hours at $80^{\circ} \mathrm{C}$. Membranes were then pre-hybridized using an oven shaker (Amersham

119 Biosciences) to control for temperature and humidity. Labeled probes were then introduced using

120 a Miniblotter 45 device (Immunetics, Immunetics, Cambridge, MA, USA), and the membranes

121 hybridized overnight at controlled temperature and humidity under gentle agitation. After

122 washing, hybridization signals were detected by chemiluminescence using CDP-Star reagent

123 (GE Healthcare), and membranes were exposed to ECL Hyperfilm-MP during 60 minutes (GE

124 Healthcare). Hyperfilm images were digitized and quantified using TotalLab Quant analysis

125 software (TotalLab Life Science Analysis Essentials, Newcastle upon Tyne, UK).

\section{Statistical analyses}

127 To adjust for any potential variation in the volume or weight of the samples, the mean proportion

128 was used by calculating the percentage of each detected microbial species within each sample

129 and then the percentages were averaged for each collection site using the formula below

130 Mean proportions $=\left[\left(\mathrm{X}_{1} / \mathrm{Y}_{1}\right)+\left(\mathrm{X}_{2} / \mathrm{Y}_{2}\right)+\left(\mathrm{X}_{3} / \mathrm{Y}_{3}\right) \ldots\left(\mathrm{X}_{\mathrm{Z}} / \mathrm{Y}_{\mathrm{Z}}\right)\right] / \mathrm{Z} \times 100$

$131 \mathrm{X}=$ Detected signals from a species in a particular sample.

$132 \mathrm{Y}=$ Total detected signals from the corresponding sample.

$133 Z=$ Number of samples: 10 for samples taken from tongue and sites of ARONJ, and 8 for 134 samples taken from the teeth (2 edentate patients). 
135 Multiple sites of exposed bone within the same patient were averaged and considered one

136 sample. Spearman non-parametric correlation was used to assess the relationship between the

137 proportions of bacterial species colonizing the exposed bone, adjacent teeth, contra-lateral teeth

138 and tongue. Pairwise Wilcoxon signed rank test was used for within-group comparisons of mean

139 bacterial proportions colonizing the adjacent and contra-lateral teeth. Mann-Whitney U test was

140 used for comparisons of mean proportions of bacteria colonizing the sites of ARONJ and tongue

141 between patients with or without dentures. All statistical analyses were performed using SPSS 19

142 with significance level $\mathrm{p}<0.05$.

\section{Results}

\section{Patients' characteristics}

145 ARONJ was noted clinically as exposed bone surrounded by inflamed soft tissues. A total of 10

146 ARONJ patients $($ male $=5$, female $=5$, mean age $=73.2 \pm 10.8$ years $)$ were identified. Patients'

147 characteristics are presented in Table 2. Exposure to bisphosphonates ranged from 1 to 8 years;

148 subcutaneous denosumab and intravenous bisphosphonates were prescribed for 7 patients as

149 adjuvant cancer medication, and oral bisphosphonates for 3 patients to treat osteoporosis;

150 prednisone was the most frequent co-medication and was prescribed to 4 patients; seven patients

151 had taken antibiotics in the 6 months prior to sample collection for systemic and/or oral infection

152 control; only 2 patients were totally edentulous; multiple sites of bone exposure were noted in 3

153 patients.

\section{Microbiological results}


155 All probes hybridized with microbial whole genome extracted from the oral samples of ARONJ 156 patients. Most dominant bacteria in the site of exposed bone were E. corrodens, S. gordonii, S. 157 constelatus, F. nucleatum, E faecalis and S. aureus. E. corrodens was the only bacterial species 158 detected in all sites of exposed bone (Table 3). The most dominant bacterial species colonizing 159 the teeth were V. parvula, T. forsythia, S. gordonii, S. oralis, S. mitis and T. denticola. The 160 tongue was mainly colonized by $V$. parvula, S. mitis, S. gordonii, S. parasanguinis, S. oralis and 161 S. aureus (Table 3). The mean proportions of bacteria per collection site are shown in Figure 1.

163 Significant correlations were found when assessing the relationships between the mean 164 proportions of the bacterial species colonizing the adjacent teeth, contra-lateral teeth and tongue.

165 However, no correlation was found between the mean proportions of bacterial species colonizing 166 the exposed bone and any other collection site in the mouth of ARONJ patients (Figure 2).

168 The mean proportion of $S$. mutans was significantly higher in the teeth adjacent to the exposed

169 bone compared to the contra-lateral teeth (Figure 1). Conversely, the mean proportions of $C$. 170 krusei, K. pneumonia and $N$. mucosa were significantly higher in the contra-lateral teeth when 171 compared to the teeth adjacent to the exposed bone. E. faecalis displayed the same tendency but 172 the difference did not reach statistical significance $(\mathrm{p}=0.07)$ (Figure 1).

173 Only few species showed statistically significant difference when comparing patients with or 174 without dentures. Significantly higher proportions of P.micra $(p=0.019)$ and $T$ denticola $175(p=0.038)$ was found in the sites of exposed bone in patients wearing dentures compared to 176 patients without dentures. C.krusei and M.salivarium had the same trend but did not reach 177 statistically significant difference $(\mathrm{p}=0.067)$. The proportions of E. Faecalis was significantly 
178 higher $(p=0.038)$, and the proportions of T.denticola tended to be significantly higher $(p=0.067)$

179 in bacterial samples taken from the tongue of patients without dentures compared to patients with

180 dentures

\section{Discussion}

182 Only few studies in the literature used molecular techniques to investigate the role of oral 183 microbiota in the development of ARONJ (Ji et al., 2012; Wei et al., 2012). In the present 184 investigation we employed the DNA checkerboard method using 43 genomic DNA probes 185 prepared from human oral bacteria and fungi to assess any link between microorganisms 186 colonizing the site of ARONJ and other sites of the oral cavity such as the teeth and the tongue.

187 Our study showed that the exposed bone exhibited a distinguishable bacterial profile from the 188 other sites of the oral cavity. The remarkable presence of E. corrodens, in all sites of ARONJ, 189 independently from its mean proportions, suggests a role of this species in the development of 190 bone necrosis. This is consistent with previous reviews suggesting certain presence of Eikenella 191 in the sites of bisphosphonates osteonecrosis (Hinson et al. 2014). E. corrodens is a Gram192 negative facultative anaerobic bacillus and part of Socransky's green complex (Socransky et al. 193 1998). It has been identified in dentoalveolar abscess, osteoradionecrosis and it is possibility 194 implicated in periodontal diseases (Kolenbrander et al. 2002; Store et al. 2005). In addition, the 195 abundant presence of both $S$. constelatus and $F$. nucleatum was noted in the present 196 investigation. These species are recognized as opportunistic pathogenic bacteria. They are part of 197 Socransky's orange complex, and could be associated with infection of non-periodontal sites 198 (Socransky et al. 1998; Store et al. 2005). Bacteria from the red complex (T. forsythia, P. 199 gingivalis and $T$. denticola) were also found in our samples from exposed bone but in less 
200 abundance. Species of this complex exhibit close relationship with species from the orange 201 complex. They might not be able to colonize without the previous presence of bacteria from the 202 orange complex (Socransky et al. 1998). In our cohort, patients wearing dentures seemed to have 203 higher bacterial proportions from Socransky's red complex in the sites of exposed bone 204 compared to patients without dentures.

205 In the present investigation, E. corrodens, S. constelatus and F. nucleatum were also found in 206 almost all the samples collect from the adjacent and contra-lateral teeth, and detected in lower 207 abundance in samples taken from the tongue. This suggests that bacteria from green and orange 208 complexes colonizing the teeth and tongue of ARONJ patients might be synergistically 209 implicated in the development of necrosis.

210 Furthermore, S. aureus was the 6th most dominant species in the site of exposed bone and had 211 high proportions in samples taken from the tongue. The remarkable presence of $S$. aureus in 212 bone samples could be explained by this species' ability to adhere to bone by means of its 213 collagen receptors (Holderbaum et al. 1987). Its high incidence in samples taken from the 214 exposed bone could also be related to an enhanced adhesion promoted by bisphosphonates 215 (Kobayashi et al. 2010; Kos et al. 2013).

216 A particular feature of bone infections by $S$. aureus and E. corrodens species is the destruction of 217 mineralized tissue resulting from the ability of $S$. aureus protein A to activate nuclear factor 218 kappa B, which in turn activates osteoclastic activity in the area of infection (Claro et al. 2013).

219 E. corrodens also produces a surface-associated material that stimulates the synthesis of Tumor 220 Necrosis Factor alpha (TNFa) leading to potent bone resorption (Meghji et al. 1995; Meghji et 221 al. 1994). Although bone resorption was not measured clinically or radiographically in the 
222 current investigation, it was not visually apparent in our cohort of patients. It is known that

223 bisphosphonates and RANKL inhibitors decreases osteoclastic activity and reduce bone

224 resorption. Therefore, the absence of bone resorption in the area of necrotic bone could be the

225 direct result of bisphosphonates and RANKL inhibitors administration (Jabbour et al. 2016).

226 The results of the present study showed rare presence of $A$. actinomycetemcomitans in the sites

227 of ARONJ. This observation is consistent with Wei et al. who reported low incidence of $A$.

228 actinomycetemcomitans in their bone samples using molecular techniques (Wei et al. 2012).

229 However, considerable presence of A. actinomycetemcomitans was previously observed using

230 histological sections (Hansen et al. 2007; Hansen et al. 2006; Hinson et al. 2014). Although $A$.

231 actinomycetemcomitans has often been associated with periodontal diseases (Amano 2010;

232 Henderson et al. 2010; Slots and Ting 1999), its sporadic presence in the area of exposed bone in

233 our samples suggests a minor role of this species in the development of ARONJ.

234 In the current investigation, significant correlations were found between the mean bacterial

235 proportions colonizing the adjacent teeth, contra-lateral teeth and tongue. These correlations

236 suggest that the prescribed medications had similar impact on the bacteria colonizing the surface

237 of vital structures such as teeth and tongue, but not the surface of necrotic exposed bone.

238 Differences noted in the proportions of species colonizing the exposed bone, tongue and the

239 supragingival dental biofilm could be attributed to the distinct surface characteristics of each, and

240 the inherent ability of specific microbial species to selectively colonize them. In the present

241 study, we included samples from the tongue since previous reports showed that the dorsum of the

242 tongue could house an organized biofilm and act as reservoir for the re-colonization of oral

243 surfaces by pathogenic species (Faveri et al. 2006; Mager et al. 2003). 
244 Differences in the mean proportions of C. krusei, E. faecalis, K. pneumonia, N. mucosa and $S$. 245 mutans colonizing the adjacent and contra-lateral teeth, although significant, were small (Figure

246 1). In addition, there was a similar frequency of these species in the adjacent and contra-lateral

247 teeth (Table 3), suggesting that they might not be directly related to the development of ARONJ.

248 In future studies, a longitudinal design could be useful to further investigate the link between 249 bacterial complexes and development of ARONJ. Although the cross-sectional design of the 250 current investigation provided information on the microbial species associated with ARONJ, it 251 does not provide information about the sequence of events that led to ARONJ and whether 252 ARONJ is the result of microbial infection with bacteria colonizing the teeth and tongue. Larger 253 number of patients is desired to better understand this link and whether other factors such as 254 medications, gender or ethnicity could play a role in the development of ARONJ.

\section{Acknowledgements}

256 Zaher Jabbour received awards from the Fonds de recherche en santé du Québec (FRSQ), the 257 FRSQ-Réseau de recherche en santé buccodentaire et osseuse (RSBO) and the Fondation de 258 l'Ordre des dentistes du Québec (FODQ). The study was made possible through operating funds 259 from FODQ and Synthes Canada, and infrastructure support from the FRQ-S-RSBO and the Jo 260 Miller Orthopaedic Research Fund.

\section{Conflict of Interest}

262 None. 


\section{References}

264

265

266

267

268

269

270

271

272

273

274

275

276

277

278

279

280

281

282

283

284

285

286

287

288

289

290

291

292

Aas, J.A., Paster, B.J., Stokes, L.N., Olsen, I., and Dewhirst, F.E. 2005. Defining the normal bacterial flora of the oral cavity. J. Clin. Microbiol. 43(11): 5721-5732. doi: 43/11/5721 [pii] 10.1128/JCM.43.11.5721-5732.2005.

Amano, A. 2010. Bacterial adhesins to host components in periodontitis. Periodontol. 2000 52(1): 12-37. doi: 10.1111/j.1600-0757.2009.00307.x.

Bundred, N. 2012. Antiresorptive therapies in oncology and their effects on cancer progression. Cancer Treat. Rev. 38(6): 776-786. doi: 10.1016/j.ctrv.2012.02.002.

Claro, T., Widaa, A., McDonnell, C., Foster, T.J., O'Brien, F.J., and Kerrigan, S.W. 2013. Staphylococcus aureus protein A binding to osteoblast tumour necrosis factor receptor 1 results in activation of nuclear factor kappa $B$ and release of interleukin- 6 in bone infection.

Microbiology 159(Pt 1): 147-154. doi: 10.1099/mic.0.063016-0.

Coleman, R.E., and McCloskey, E.V. 2011. Bisphosphonates in oncology. Bone 49(1): 71-76. doi: 10.1016/j.bone.2011.02.003.

do Nascimento, C., Barbosa, R.E., Issa, J.P., Watanabe, E., Ito, I.Y., and de Albuquerque Junior, R.F. 2009. Use of checkerboard DNA-DNA hybridization to evaluate the internal contamination of dental implants and comparison of bacterial leakage with cast or pre-machined abutments. Clin. Oral Implants Res. 20(6): 571-577. doi: CLR1663 [pii] 10.1111/j.1600-0501.2008.01663.x.

do Nascimento, C., de Albuquerque, R.F., Jr., Monesi, N., and Candido-Silva, J.A. 2010. Alternative method for direct DNA probe labeling and detection using the checkerboard hybridization format. J. Clin. Microbiol. 48(8): 3039-3040. doi: JCM.00390-10 [pii] 10.1128/JCM.00390-10.

Faveri, M., Feres, M., Shibli, J.A., Hayacibara, R.F., Hayacibara, M.M., and de Figueiredo, L.C. 2006. Microbiota of the dorsum of the tongue after plaque accumulation: an experimental study in humans. J. Periodontol. 77(9): 1539-1546. doi: 10.1902/jop.2006.050366.

Hansen, T., Kunkel, M., Springer, E., Walter, C., Weber, A., Siegel, E., and Kirkpatrick, C.J. 2007. Actinomycosis of the jaws--histopathological study of 45 patients shows significant involvement in bisphosphonate-associated osteonecrosis and infected osteoradionecrosis. Virchows Arch. 451(6): 1009-1017. doi: 10.1007/s00428-007-0516-2. 
293

294

295

296

297

298

299

300

301

302

303

304

305

306

307

308

309

310

311

312

313

314

315

316

317

318

319

320

321

322

323

Hansen, T., Kunkel, M., Weber, A., and James Kirkpatrick, C. 2006. Osteonecrosis of the jaws in patients treated with bisphosphonates - histomorphologic analysis in comparison with infected osteoradionecrosis. J. Oral Pathol. Med. 35(3): 155-160. doi: JOP391 [pii] 10.1111/j.1600-0714.2006.00391.x.

Henderson, B., Ward, J.M., and Ready, D. 2010. Aggregatibacter (Actinobacillus)

actinomycetemcomitans: a triple A* periodontopathogen? Periodontol. 2000 54(1): 78-105. doi: 10.1111/j.1600-0757.2009.00331.x.

Hinson, A.M., Smith, C.W., Siegel, E.R., and Stack, B.C., Jr. 2014. Is bisphosphonate-related osteonecrosis of the jaw an infection? A histological and microbiological ten-year summary. International journal of dentistry 2014: 452737. doi: 10.1155/2014/452737.

Holderbaum, D., Spech, T., Ehrhart, L.A., Keys, T., and Hall, G.S. 1987. Collagen binding in clinical isolates of Staphylococcus aureus. J. Clin. Microbiol. 25(12): 2258-2261.

Jabbour, Z., do Nascimento, C., El-Hakim, M., Henderson, J.E., and de Albuquerque Junior, R.F. 2016. Bacterial profile and bone healing in rats receiving cancer therapeutic doses of bisphosphonates and corticosteroids: a pilot study. Int J Oral Maxillofac Surg. doi: 10.1016/j.ijom.2015.12.017.

Jabbour, Z., do Nascimento, C., Kotake, B.G., El-Hakim, M., Henderson, J.E., and de Albuquerque Junior, R.F. 2013. Assessing the oral microbiota of healthy and alcohol-treated rats using whole-genome DNA probes from human bacteria. Arch. Oral Biol. 58(3): 317-323. doi: 10.1016/j.archoralbio.2012.07.017.

Ji, X., Pushalkar, S., Li, Y., Glickman, R., Fleisher, K., and Saxena, D. 2012. Antibiotic effects on bacterial profile in osteonecrosis of the jaw. Oral Dis. 18(1): 85-95. doi: 10.1111/j.16010825.2011.01848.x.

Kobayashi, Y., Hiraga, T., Ueda, A., Wang, L., Matsumoto-Nakano, M., Hata, K., Yatani, H., and Yoneda, T. 2010. Zoledronic acid delays wound healing of the tooth extraction socket, inhibits oral epithelial cell migration, and promotes proliferation and adhesion to hydroxyapatite of oral bacteria, without causing osteonecrosis of the jaw, in mice. J. Bone Miner. Metab. 28(2): 165-175. doi: 10.1007/s00774-009-0128-9.

Kolenbrander, P.E., Andersen, R.N., Blehert, D.S., Egland, P.G., Foster, J.S., and Palmer, R.J., Jr. 2002. Communication among oral bacteria. Microbiol. Mol. Biol. Rev. 66(3): 486-505, table of contents. 
324 Kos, M., Junka, A., Smutnicka, D., Bartoszewicz, M., Kurzynowski, T., and Gluza, K. 2013.

325 Pamidronate enhances bacterial adhesion to bone hydroxyapatite. Another puzzle in the 326 pathology of bisphosphonate-related osteonecrosis of the jaw? J. Oral Maxillofac. Surg. 71(6):

327 1010-1016. doi: 10.1016/j.joms.2012.12.005.

328

329

Mager, D.L., Ximenez-Fyvie, L.A., Haffajee, A.D., and Socransky, S.S. 2003. Distribution of selected bacterial species on intraoral surfaces. J. Clin. Periodontol. 30(7): 644-654.

Meghji, S., Henderson, B., Kirby, A., Newman, H.N., and Wilson, M. 1995. Serum antibody response to surface-associated material from periodontopathogenic bacteria. FEMS Immunol. Med. Microbiol. 10(2): 101-108.

Meghji, S., Wilson, M., Barber, P., and Henderson, B. 1994. Bone resorbing activity of surfaceassociated material from Actinobacillus actinomycetemcomitans and Eikenella corrodens. J. Med. Microbiol. 41(3): 197-203.

Otto, S., Hafner, S., Mast, G., Tischer, T., Volkmer, E., Schieker, M., Sturzenbaum, S.R., von Tresckow, E., Kolk, A., Ehrenfeld, M., and Pautke, C. 2010. Bisphosphonate-related osteonecrosis of the jaw: is $\mathrm{pH}$ the missing part in the pathogenesis puzzle? J. Oral Maxillofac. Surg. 68(5): 1158-1161. doi: S0278-2391(09)01493-1 [pii] 10.1016/j.joms.2009.07.079.

Pushalkar, S., Li, X., Kurago, Z., Ramanathapuram, L.V., Matsumura, S., Fleisher, K.E., Glickman, R., Yan, W., Li, Y., and Saxena, D. 2014. Oral microbiota and host innate immune response in bisphosphonate-related osteonecrosis of the jaw. Int J Oral Sci 6(4): 219-226. doi: 10.1038/ijos.2014.46.

Ruggiero, S.L., Dodson, T.B., Fantasia, J., Goodday, R., Aghaloo, T., Mehrotra, B., and O'Ryan, F. 2014. American Association of Oral and Maxillofacial Surgeons Position Paper on Medication-Related Osteonecrosis of the Jaw-2014 Update. Journal of oral and maxillofacial surgery : official journal of the American Association of Oral and Maxillofacial Surgeons.

Sedghizadeh, P.P., Yooseph, S., Fadrosh, D.W., Zeigler-Allen, L., Thiagarajan, M., Salek, H., Farahnik, F., and Williamson, S.J. 2012. Metagenomic investigation of microbes and viruses in patients with jaw osteonecrosis associated with bisphosphonate therapy. Oral surgery, oral medicine, oral pathology and oral radiology 114(6): 764-770. doi: 10.1016/j.oooo.2012.08.444.

Slots, J., and Ting, M. 1999. Actinobacillus actinomycetemcomitans and Porphyromonas gingivalis in human periodontal disease: occurrence and treatment. Periodontol. 2000 20: 82121. 
356 Socransky, S.S., Haffajee, A.D., Cugini, M.A., Smith, C., and Kent, R.L., Jr. 1998. Microbial 357 complexes in subgingival plaque. J. Clin. Periodontol. 25(2): 134-144.

358 Socransky, S.S., Haffajee, A.D., Smith, C., Martin, L., Haffajee, J.A., Uzel, N.G., and Goodson, 359 J.M. 2004. Use of checkerboard DNA-DNA hybridization to study complex microbial

360 ecosystems. Oral Microbiol. Immunol. 19(6): 352-362. doi: OMI168 [pii]

361 10.1111/j.1399-302x.2004.00168.x.

362 Store, G., Eribe, E.R., and Olsen, I. 2005. DNA-DNA hybridization demonstrates multiple

363 bacteria in osteoradionecrosis. Int J Oral Maxillofac Surg 34(2): 193-196. doi:

364 10.1016/j.ijom.2004.06.010.

365 Sunde, P.T., Tronstad, L., Eribe, E.R., Lind, P.O., and Olsen, I. 2000. Assessment of

366 periradicular microbiota by DNA-DNA hybridization. Endod Dent Traumatol 16(5): 191-196.

367 Wei, X., Pushalkar, S., Estilo, C., Wong, C., Farooki, A., Fornier, M., Bohle, G., Huryn, J., Li, 368 Y., Doty, S., and Saxena, D. 2012. Molecular profiling of oral microbiota in jawbone samples of 369 bisphosphonate-related osteonecrosis of the jaw. Oral Dis. doi: 10.1111/j.1601-

$370 \quad$ 0825.2012.01916.x. 
372 Figure 1: Mean proportions $(\% \pm$ SEM) of the microbial species detected. Statistically

373 significant difference between the mean bacterial species colonizing the adjacent and contra-

374 lateral teeth (Pairwise Wilcoxon signed rank test *p $\leq 0.05,{ }^{* *} \mathrm{p}<0.01, \dagger \mathrm{p}=0.07$ ).

375

376 Figure 2: Scatter plots of the mean bacterial proportions (\%) showing significant correlations

377 between the bacteria colonizing the adjacent teeth, contra-lateral teeth and tongue. No correlation

378 was found between the bacteria colonizing the exposed bone and other evaluated sites of the

379 mouth. 
Table 1: Human DNA microbial species used to prepare probes for cross-reaction with species extracted from the oral cavity of humans.

\begin{tabular}{|c|c|}
\hline Species & Reference \\
\hline Aggregatibacter actinomycetemcomitans a & ATCC 29523 \\
\hline Aggregatibacter actinomycetemcomitans $b$ & ATCC 29522 \\
\hline Bacteroides fragilis & ATCC 25285 \\
\hline Campylobacter rectus & ATCC 33238 \\
\hline Candida albicans & ATCC 10231 \\
\hline Candida dubliniensis & ATCC MYA 646 \\
\hline Candida glabrata & ATCC 90030 \\
\hline Candida krusei & ATCC 6258 \\
\hline Candida tropicalis & ATCC 750 \\
\hline Capnocytophaga gingivalis & ATCC 33624 \\
\hline Eikenella corrodens & ATCC 23834 \\
\hline Enterococcus faecalis & ATCC 51299 \\
\hline Escherichia coli & ATCC 10798 \\
\hline Fusobacterium nucleatum & ATCC 25586 \\
\hline Fusobacterium periodonticum & ATCC 33693 \\
\hline Klebsiella pneumoniae & ATCC 700721 \\
\hline Lactobacillus casei & ATCC 393 \\
\hline Mycoplasma salivarium & ATCC 23064 \\
\hline Neisseria mucosa & ATCC 25996 \\
\hline Parvimonas micra & ATCC 33270 \\
\hline Peptostreptococcus anaerobius & ATCC 49031 \\
\hline Porphyromonas endodontalis & ATCC 35406 \\
\hline Porphyromonas gingivalis & ATCC 33277 \\
\hline Prevotella intermedia & ATCC 25611 \\
\hline Prevotella melaninogenica & ATCC 25845 \\
\hline Prevotella nigrescens & ATCC 33563 \\
\hline Pseudomonas aeruginosa & ATCC 27853 \\
\hline Pseudomonas putida & ATCC 12633 \\
\hline Solobacterium moorei & CCUG 39336 \\
\hline Staphylococcus aureus & ATCC 25923 \\
\hline Staphylococcus pasteuri & ATCC 51129 \\
\hline Streptococcus constellatus & ATCC 27823 \\
\hline Streptococcus gordonii & ATCC 10558 \\
\hline Streptococcus mitis & ATCC 49456 \\
\hline Streptococcus mutans & ATCC 25175 \\
\hline Streptococcus oralis & ATCC 35037 \\
\hline Streptococcus parasanguinis & ATCC 15911 \\
\hline Streptococcus salivarius & ATCC 25975 \\
\hline Streptococcus sanguinis & ATCC 10556 \\
\hline Streptococcus sobrinus & ATCC 27352 \\
\hline Tannerella forsythia & ATCC 43037 \\
\hline Treponema denticola & ATCC 35405 \\
\hline Veillonella parvula & ATCC 10790 \\
\hline
\end{tabular}


ection.

anti-

\begin{tabular}{|c|c|c|c|c|c|c|c|}
\hline $\begin{array}{l}\text { osteoclastic } \\
\text { drug }\end{array}$ & $\begin{array}{l}\text { anti-osteoclastic } \\
\text { drug stopped }\end{array}$ & $\begin{array}{l}\text { Co-medications } \\
\text { (last } 6 \text { months) }\end{array}$ & $\begin{array}{c}\text { Antibiotics } \\
\text { (last } 6 \text { months) }\end{array}$ & $\begin{array}{c}\text { Site of ARONJ } \\
\text { (stage) }\end{array}$ & $\begin{array}{c}\text { Plaque } \\
\text { (adjacent teeth) }\end{array}$ & $\begin{array}{c}\text { Plaque (Contra- } \\
\text { lateral teeth) }\end{array}$ & $\begin{array}{l}\text { Presence } \\
\text { of denture }\end{array}$ \\
\hline $\begin{array}{l}\text { Zoledronic acid } \\
\qquad \text { (IV) }\end{array}$ & No & $\begin{array}{c}\text { Prednisone } \\
\text { Abiraterone } \\
\text { Sunitinib }\end{array}$ & $\begin{array}{l}\text { Amoxicillin }+ \\
\text { clavulanic acid } \\
\text { Moxifloxacin }\end{array}$ & $\begin{array}{l}\text { 44, } 43 \text { lingual ridge } \\
\text { (II) }\end{array}$ & 3 & 3 & Partial \\
\hline $\begin{array}{l}\text { Zoledronic acid } \\
\text { (IV) }\end{array}$ & Yes & Sunitinib & - & $\begin{array}{c}37,38(\mathrm{I}) \\
47(\mathrm{I})\end{array}$ & - & - & Complete \\
\hline $\begin{array}{l}\text { Zoledronic acid } \\
\text { (IV) }\end{array}$ & Yes & Prednisone & Clindamycin & $\begin{array}{l}37,38 \text { lingual ridge } \\
\text { (I) }\end{array}$ & 2 & 1 & Partial \\
\hline $\begin{array}{l}\text { Risedronate } \\
\text { (PO) }\end{array}$ & No & Prednisone & Moxifloxacin & 46 (II) & 1 & 1 & - \\
\hline $\begin{array}{l}\text { Alendronate } \\
\text { (PO) }\end{array}$ & Yes & - & Amoxicillin & 37 (I) & 1 & 1 & - \\
\hline $\begin{array}{l}\text { Denosumab } \\
\text { (SC) }\end{array}$ & No & Prednisone & - & $\begin{array}{l}36(\mathrm{I}) \\
15(\mathrm{I}) \\
\end{array}$ & $\begin{array}{l}1 \\
1 \\
\end{array}$ & $\begin{array}{l}1 \\
1 \\
\end{array}$ & - \\
\hline $\begin{array}{l}\text { Alendronate } \\
\text { (PO) }\end{array}$ & No & - & Penicillin VK & $47,46,45,44$ (II) & - & - & Complete \\
\hline $\begin{array}{l}\text { Pamidronate } \\
\text { (IV) }\end{array}$ & No & Sunitinib & $\begin{array}{l}\text { Teva-amoxicillin } \\
\text { Metranidazole }\end{array}$ & $\begin{array}{c}12 \text { buccal ridge (I) } \\
23,24,25 \text { (I) } \\
47 \text { (II) }\end{array}$ & $\begin{array}{l}3 \\
3 \\
2\end{array}$ & $\begin{array}{l}3 \\
3 \\
2\end{array}$ & - \\
\hline $\begin{array}{l}\text { Alendronate } \\
\text { (PO) } \\
\text { Pamidronate } \\
\text { (IV) }\end{array}$ & No & $\begin{array}{c}\text { Tamoxifen, } \\
\text { Aramasin }\end{array}$ & - & $\begin{array}{l}36,37 \text { lingual ridge } \\
\text { (I) }\end{array}$ & 1 & 1 & - \\
\hline $\begin{array}{l}\text { Zoledronic acid } \\
\qquad \text { (IV) }\end{array}$ & Yes & Fulvestrant, & $\begin{array}{c}\text { Amoxicillin }+ \\
\text { clavilacule acid } \\
\text { Ciprofloxacin }\end{array}$ & 47,48 (II) & 3 & 1 & - \\
\hline
\end{tabular}

ed on the gingival third with explorer, 2 = Plaque is visible, $3=$ Tooth surface covered with abundant plaqu 
Table 3: Bacterial species per collection site and their detected frequencies ordered by decreasing mean proportions illustrated in Figure 1.

\begin{tabular}{c} 
Exposed bone \\
(Number of sites=10) \\
\hline E.corrodens $(10)$ \\
S.gordonii $(8)$ \\
S.constelatus $(8)$ \\
F.nucleatum $(8)$ \\
E.faecalis $(9)$ \\
S.aureus $(8)$ \\
S.mitis $(8)$ \\
N.mucosa $(9)$ \\
T.forsythia $(9)$ \\
E.coli $(6)$ \\
S.sobrinus $(8)$ \\
P.gingivalis $(7)$ \\
P.aeruginosa $(8)$ \\
K.pneumoniae $(7)$ \\
S.parasanguinis $(5)$ \\
P.endodontalis $(8)$ \\
P.intermedia (6) \\
P.anaerobios $(8)$ \\
S.moorei $(6)$ \\
C.krusei $(7)$ \\
F.periodonticum $(7)$ \\
M.salivarium $(7)$ \\
S.pasteuri $(6)$ \\
C.glabrata $(7)$ \\
C.albicans $(7)$ \\
C.dubliniensis $(2)$ \\
S.oralis $(6)$ \\
P.melaninogenica $(6)$ \\
P.micra $(7)$ \\
L.casei $(6)$ \\
P.putida $(5)$ \\
S.salivarius $(6)$ \\
C.tropicalis $(5)$ \\
S.sanguinis $(4)$ \\
V.parvula $(4)$ \\
T.denticola $(5)$ \\
S.mutans $(4)$ \\
P.nigrescens $(5)$ \\
\end{tabular}

\begin{tabular}{c}
$\begin{array}{c}\text { Adjacent teeth } \\
\text { (Number of sites }=8)\end{array}$ \\
\hline V.parvula $(8)$ \\
T.forsythia $(8)$ \\
S.gordonii $(8)$ \\
S.mitis $(8)$ \\
S.oralis $(8)$ \\
S.mutans $(8)$ \\
S.sanguinis $(8)$ \\
Aa_a $(8)$ \\
S.sobrinus $(8)$ \\
T.denticola $(6)$ \\
P.gingivalis $(7)$
\end{tabular}

S.parasanguinis (8)

P.melaninogenica (6)

S.constelatus (8)

F.nucleatum (7)

S.pasteuri (7)

S.salivarius (8)

S.aureus (7)

C.gingivalis (6)

P.nigrescens (7)

P.intermedia (4)

C.albicans (6)

P.putida (8)

P.micra (6)

L.casei (7)

S.moorei (7)

C.rectus (5)

M.salivarium (7)

C.glabrata (7)

F.periodonticum (6)

E.corrodens (7)

P.anaerobios (7)

P.endodontalis (7)

E.coli (6)

K.pneumoniae (7)

B.fragilis (5)

C.dubliniensis (6)

E.faecalis (7)

$A a \_b$ (4)

N.mucosa (7)

P.aeruginosa (6)
Contra-lateral teeth (Number of sites $=8$ )

V.parvula (8)

S.gordonii (8)

S.oralis (8)

T.denticola (7)

T.forsythia (8)

S.mitis (8)

S.sanguinis (8)

P.intermedia (6)

S.mutans (8)

P.melaninogenica (7)

C.gingivalis (7)

F.nucleatum (8)

S.pasteuri (8)

P.micra (8)

S.parasanguinis (8)

Aa_a (8)

S.aureus (8)

S.sobrinus (8)

P.gingivalis (8)

P.nigrescens (8)

E.corrodens (8)

S.moorei (8)

C.rectus (7)

F.periodonticum (8)

S.salivarius (8)

L.casei (8)

P.putida (8)

M.salivarium (8)

S.constelatus (8)

P.anaerobios (8)

K.pneumoniae (8)

B.fragilis (6)

C.glabrata (8)

E.faecalis (8)

Aa_b (6)

P.endodontalis (8)

N.mucosa (8)

E.coli (6)

C.albicans (6)

P.aeruginosa (8)

C.tropicalis (8)
Tongue

(Number of sites $=10$ )

V.parvula (10)

S.mitis (10)

S.gordonii (8)

S.parasanguinis (10)

S.oralis (10)

S.aureus (10)

P.intermedia (7)

S.mutans (10)

S.sanguinis (10)

E.corrodens (9)

Aa_a (10)

P.gingivalis (7)

P.melaninogenica (7)

T.forsythia (10)

S.sobrinus (10)

S.pasteuri (9)

M.salivarium (10)

C.gingivalis (8)

$A a \_b$ (7)

L.casei (10)

T.denticola (7)

P.nigrescens (7)

P.putida (8)

S.moorei (8)

C.rectus (6)

F.nucleatum (7)

E.faecalis (9)

K.pneumoniae (8)

P.micra (7)

S.salivarius (7)

N.mucosa (4)

C.albicans (4)

S.constelatus (2)

E.coli (3)

P.endodontalis (3)

P.anaerobios (3)

B.fragilis (2)

F.periodonticum (1)

P.aeruginosa (1)

C.tropicalis (1)

C.glabrata (0) 


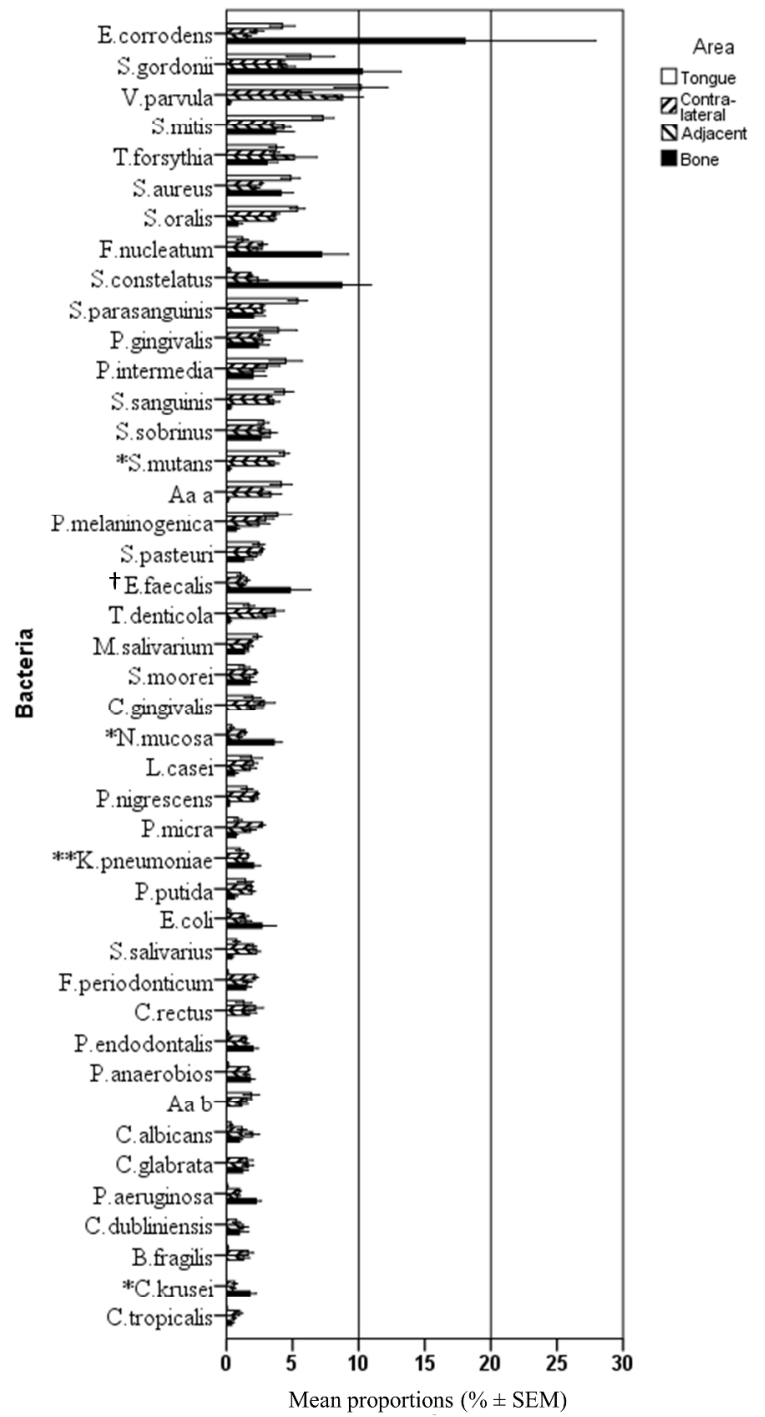

Figure 1: Mean proportions ( $\% \pm$ SEM) of the microbial species detected. Statistically significant difference between the mean bacterial species colonizing the adjacent and contra-lateral teeth (Pairwise Wilcoxon signed rank test $* p \leq 0.05, * * p<0.01,+p=0.07)$ $750 \times 1422 \mathrm{~mm}(96 \times 96$ DPI $)$ 


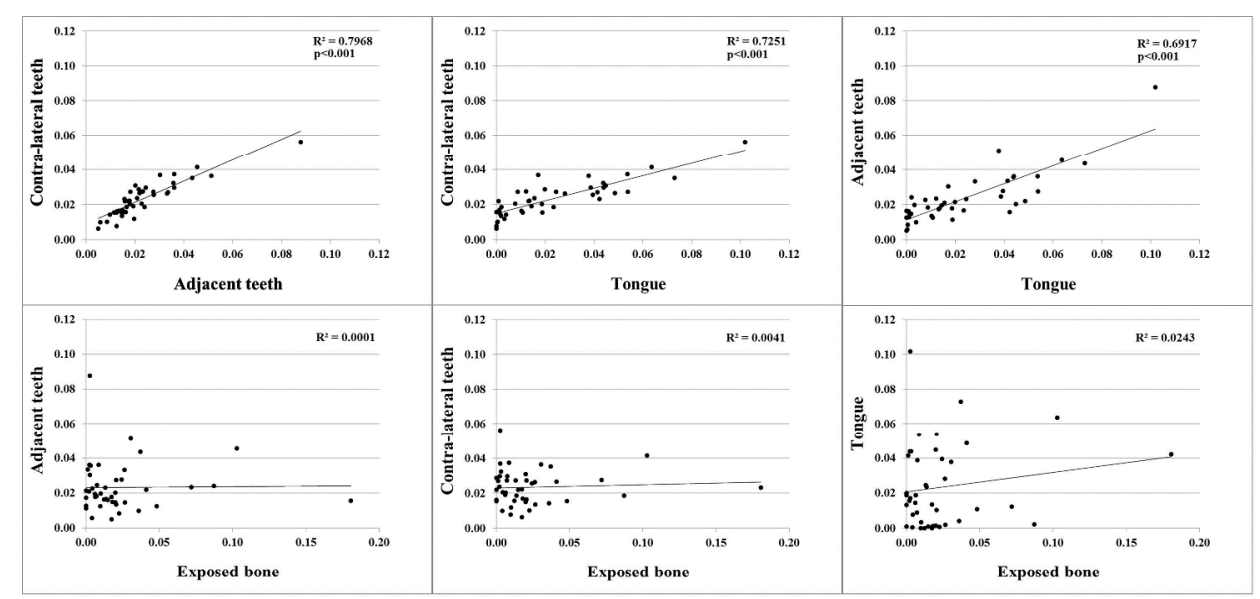

Figure 2: Scatter plots of the mean bacterial proportions (\%) showing significant correlations between the bacteria colonizing the adjacent teeth, contra-lateral teeth and tongue. No correlation was found between the bacteria colonizing the exposed bone and other evaluated sites of the mouth.

$$
1270 \times 952 \mathrm{~mm}(61 \times 61 \mathrm{DPI})
$$

